\title{
Analisis Persebaran UMKM Kota Malang Menggunakan Cluster K-means
}

\author{
Puntoriza $^{1}$, Charitas Fibriani ${ }^{2}$ \\ Fakultas Teknologi Informasi, Program Studi Sistem Informasi \\ Universitas Kristen Satya Wacana \\ e-mail: ${ }^{1} 682013018 @$ student.uksw.edu, ${ }^{2}$ charitas.fibriani@uksw.edu \\ Diterima: 23 Maret 2020; Direvisi: 16 Mei 2020; Disetujui: 20 Mei 2020
}

\begin{abstract}
Abstrak
UMKM (Usaha Mikro Kecil dan Menengah) merupakan usaha produktif yang telah terbukti memberikan lapangan kerja dan menjadi penggerak roda perekonomian di Indonesia. Kota Malang dianggap memiliki potensi besar di sektor UMKM. Di sisi lain, UMKM juga menghadapi berbagai masalah, seperti keterbatasan modal kerja, kurangnya pembinaan terhadap sumber daya manusia, dan lain sebagainya. Pengelompokan UMKM di Kota Malang dapat memudahkan pemerintah terkait dalam hal memilih peminjaman modal, menentukan potensi usaha dan menetapkan strategi pemasaran. Pada penelitian ini, pengelompokan UMKM di Kota Malang dilakukan dengan algoritma K-means cluster analysis. Hasil yang diperoleh adalah terbentuk 3 cluster, di mana algoritma K-means mengelompokkan kecamatan Blimbing ke cluster 1 , kecamatan Klojen ke cluster 2, kecamatan Sukun ke cluster 3, Kecamatan Kedung Kandang ke cluster 3, dan Kecamatan Lowokwaru ke cluster 3.
\end{abstract}

Kata kunci: k-means cluster, kota malang, umkm, weka

\begin{abstract}
MSME (Micro, Small and Medium Enterprises) is a productive business that has been provent to provide employment and drive economic development in Indonesia. Malang is consider to have great potential in the MSME sector. On the other hand, MSMEs also face various problems, such as limited working capital, lack of workforce skills, and so forth. The grouping of MSMEs in Malang can facilitate the government in terms of choosing capital loans, determining business potential and determining marketing strategies. In this study, the grouping of MSMEs in Malang was done using the K-means cluster analysis algorithm. The results obtained are formed 3 clusters, where the K-means algorithm groups Blimbing sub-district into cluster 1, Klojen subdistrict to cluster 2, Sukun sub-district to cluster 3, Kedung Kandang sub-district to cluster 3, and Lowokwaru sub-district to cluster 3.
\end{abstract}

Keywords: k-means cluster, malang city, msme, weka

\section{PENDAHULUAN}

UMKM (Usaha Mikro Kecil dan Menengah) di Indonesia mampu menyerap 85 juta hingga 107 juta tenaga kerja sampai tahun 2012. Jumlah pengusaha di Indonesia sebanyak 56.539.560 unit pada tahun tersebut. Dari jumlah tersebut, sebanyak 56.534.592 unit atau sebesar 99,99\% merupakan UMKM sedangkan sekitar 0,01\% atau sebesar 4.968 unit adalah usaha berskala besar. Hal tersebut menjelaskan bahwa UMKM merupakan usaha yang potensial untuk perkembangan ekonomi di Indonesia[[1]]. 
Meskipun UMKM di Kota Malang memiliki potensi penyerapan tenaga kerja yang tinggi, tetapi hingga saat ini masih terdapat hambatan-hambatan yang belum dapat diatasi. Hambatan utama yang sering dihadapi oleh UMKM adalah sulitnya mendapatkan permodalan, keterbatasan sumber daya manusia yang profesional, dan terbatasnya akses informasi untuk melihat peluang pasar. Pengelompokan UMKM kota Malang perlu dilakukan untuk memudahkan pemerintah dalam melakukan pengembangan UMKM di Kota Malang.

Pentingnya pengelompokan UMKM di Kota Malang agar dapat membantu pemerintah terkait untuk penetapan strategi pemasaran yang tepat sebagai prioritas utama untuk mengembangkan pasar. Oleh karena itu, pada penelitian ini dilakukan pengelompokan UMKM di Kota Malang berdasarkan klasifikasi usaha di lima kabupaten menggunakan algoritma Cluster K-Means.

K-Means Cluster Analysis merupakan salah satu metode cluster analysis non hirarki yang memasukan objek atau data kedalam satu atau lebih cluster yang sudah ditentukan berdasarkan karakteristiknya [[2]][3].

Pada penerapan metode K-Means Cluster Analysis, data yang bisa diolah dalam perhitungan adalah data numerik yang berbentuk angka. Setiap data dihitung kedekatan dengan nilai centroid yang sudah ditentukan sebelumnya, jarak terkecil antara data dengan masingmasing centroid merupakan anggota cluster yang terdekat [4].

Penelitian terdahulu yang menggunakan algoritma K-Means dilakukan oleh Ade dkk menerapkan algoritma K-means Clustering pada penyakit Menular di Kabupaten Majalengka Ade dkk menginput sampel data sebanyak 32 data dan menghasilkan 6 cluster kelompok data[5]. Gustientiedina dkk melakukan clustering untuk data obat-obatan menggunakan algoritma Kmeans mencapai hasil pada iterasi ke 4 [5]. Fauziah dkk menerapkan algoritma K-means untuk clustering jurusan dan menghasilkan data cluster pada iterasi ke 3[6]. Asroni mengcluster mahasiswa berdasarkan nilai akademik untuk kandidat lomba. Terdapat 5 mahasiswa yg terpilih untuk lomba terpilih dari 5 cluster yang dihasilkan.[8]. Hendro dkk mengcluster mahasiswa untuk memprediksi waktu kelulusan berdasarkan nilai IPK dan daftar kehadiran mahasiswa[9]. Poerwanto dkk menggunakan cluster K-means untuk mengelompokan kemampuan mahasiswa. Hasilnya terdapat lebih dari 70\% mahasiswa pada kategori tinggi, 27 mahasiswa pada kategori sedang dan 3 mahasiswa pada kategori rendah [10]. Algoritma K-means juga digunakan oleh Lynda dkk untuk mengelompokan data penelitian. Menghasilkan sebanyak 16 cluster [11]. Fauziah dkk mengcluster pengunjung perpustakaan menghasilkan 3 cluster [12].

\section{METODE PENELITIAN}

\subsection{Sumber Data}

Data yang digunakan merupakan data sekunder, yaitu jumlah UMKM yang ada pada setiap kecamatan di Kota Malang. Data yang digunakan bertipe data kuantitatif didapatkan dari Dinas Koperasi dan Usaha Mikro, Kecil, dan Menengah Kota Malang.

\subsection{Langkah Analisis pada gambar 1.}

1. Identifikasi Masalah Masalah yang diidentifikasi yaitu mengelompokan UMKM di tiap kabupaten di Kota Malang menjadi dua cluster. Cluster pertama untuk kabupaten yang menjadi prioritas utama untuk peminjaman modal dan pengembangan pasar. Sedangkan cluster kedua untuk kabupaten non prioritas.

2. Studi Pustaka

Studi literatur dilakukan untuk melengkapi pengetahuan dasar dan teori-teori yang berasal dari buku-buku, jurnal, maupun media internet.

3. Pengumpulan Data 
Data yang digunakan adalah data jumlah UMKM yang ada di masing-masing kecamatan di Kota Malang yang didapatkan dari Dinas Koperasi dan Usaha Mikro, Kecil, dan Menengah Kota Malang.

4. Preprocessing

Pada tahap ini, jenis usaha yang ada dikelompokan menjadi satu kategori. Contohnya pada kecamatan Blimbing terdapat jenis usaha keripik bawang, marning jagung, dan rengginang. Ketiga jenis usaha tersebut bisa dikategorikan menjadi kategori snack. Proses ini dilakukan pada semua jenis usaha di lima kecamatan Kota Malang

5. Proses Clustering dengan Metode K-Means

Data yang digunakan pada proses clustering ini adalah kategori jenis usaha yang sudah diolah pada tahap Preprocessing. Selanjutnya cluster dibagi menjadi tiga dimana Cluster pertama untuk kategori tinggi, cluster kedua untuk kategori sedang, dan cluster ketiga untuk kategori rendah.

6. Evaluasi

Tahap ini mengevaluasi hasil cluster awal, cluster centroid dan penetapan clustering.

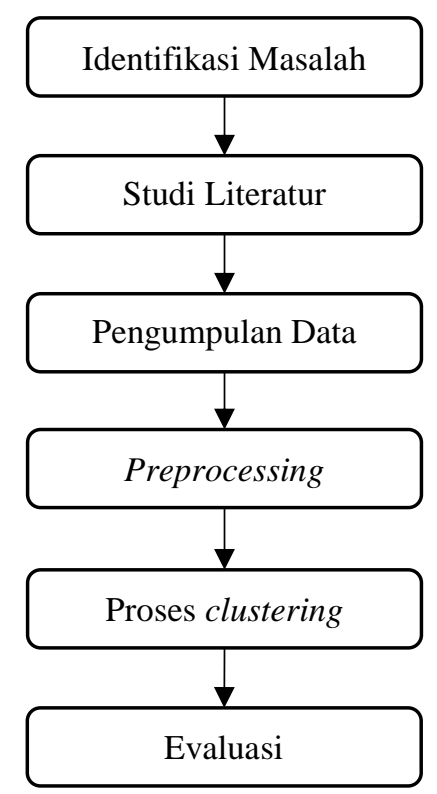

Gambar 1. Langkah-Langkah Penelitian

2.3. Tahap Perhitungan Algoritma K-means seperti pada gambar 2.

1. Menentukan Banyaknya Cluster

Penentuan banyaknya cluster harus kurang dari banyaknya data. Banyaknya cluster yang ditentukan sebanyak 3 cluster dengan urutan prioritas tinggi, sedang, rendah untuk pengembangan pasar. Cluster 1 (tinggi), cluster 2 (sedang), dan cluster 3 (rendah.)

2. Menentukan Nilai Centroid Awal

Centroid awal bisa ditentukan secara acak.

3. Menghitung Jarak Data Terhadap Masing-masing Centroid

Perhitungan jarak data terhadap centroid menggunakan rumus Euclidian Distance pada persamaan (1) [13].

$d_{i j}=\sqrt{\sum_{k=1}^{n}\left(x_{i k}-x_{j k}\right)^{2}}$ 


\section{Keterangan:}

$\mathrm{d}_{\mathrm{ij}}=$ jarak data ke-i dan data ke-j

$\mathrm{n}=$ Banyak data

$\mathrm{x}_{\mathrm{ik}}=$ nilai data ke-i pada cluster $\mathrm{k}$

$\mathrm{x}_{\mathrm{jk}}=$ nilai data $\mathrm{ke}-\mathrm{j}$ pada cluster $\mathrm{k}$

4. Hitung Kembali nilai Centroid

Hitung ulang nilai centroid sampai data pada cluster tidak berubah lagi.

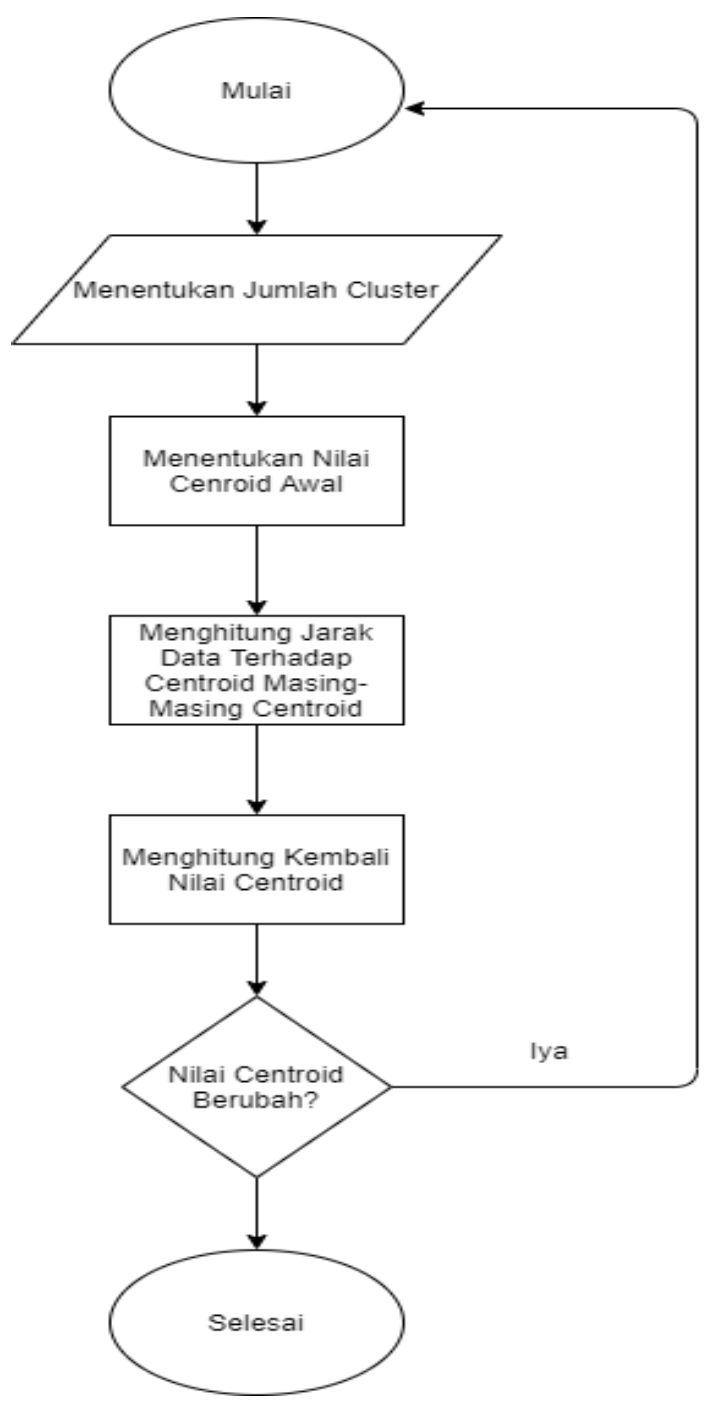

Gambar 2. Langkah-langkah Perhitungan Algoritma K-Means

\section{HASIL DAN PEMBAHASAN}

Pada data UMKM Kota Malang ini, terdapat 5 kecamatan di mana tiap kecamatan memiliki jenis produk yang berbeda untuk tiap kelurahan. Jenis-jenis produk yang dijual dikelompokkan menjadi 8 atribut sebagai berikut: saos, tempe/tahu, snack, roti, kue, minuman, masakan, dan kerajinan tangan. 
Tabel 1. Data Jumlah UMKM Berdasarkan Jenis Produk Pada Lima Kecamatan

\begin{tabular}{cccccc}
\hline Jenis Usaha & Blimbing & klojen & Kedungkandang & Sukun & lowokwaru \\
\hline saos & 2 & 47 & 2 & 2 & 0 \\
tempe/tahu & 216 & 1 & 2 & 11 & 1 \\
snack & 44 & 55 & 38 & 14 & 15 \\
roti & 22 & 14 & 4 & 1 & 3 \\
kue & 48 & 106 & 4 & 4 & 8 \\
minuman & 22 & 22 & 10 & 4 & 1 \\
masakan & 4 & 5 & 3 & 0 & 0 \\
Kerajinan tangan & 1 & 0 & 0 & 0 & 0 \\
\hline
\end{tabular}

Pengelompokan UMKM di Kota Malang dilakukan dengan mempertimbangkan 8 atribut pada tabel 1 yaitu jenis-jenis produk yang dijual. Tahapan awal dari proses clustering adalah pembentukan nilai centroid awal secara random. Selanjutnya membagi cluster menjadi 3 pada tabel 2 yaitu cluster 1 (tinggi), cluster 2 (sedang), cluster 3 (rendah). Pembagian jumlah cluster harus kurang dari jumlah data.

Tabel 2. Penetapan Cluster Awal

\begin{tabular}{cc}
\hline Cluster & Anggota \\
\hline 1 & $2,216,44,22,48,22,4,1$ \\
2 & $47,1,55,14,106,22,5,0$ \\
3 & $2,2,38,4,4,10,3,0$ \\
\hline
\end{tabular}

Tahapan selanjutnya adalah menghitung jarak centroid dan pengalokasian objek kedalam masing-masing cluster menggunakan rumus pada persamaan (1).

Tabel 3. Pengulangan 1 Perhitungan Jarak Centroid 1

\begin{tabular}{|c|c|c|}
\hline Jarak data dengan Centroid 1 & Euclidian distance & Hasil \\
\hline $\mathrm{d}\left(\right.$ blimbing,$\left.c_{1}\right)$ & $\begin{array}{c}\overline{(2-2)^{2}+(216-216)^{2}+(44-44)^{2}} \\
+(22-22)^{2}+(48-48)^{2} \\
+(22-22)^{2}+(4-4)^{2}+(1-1)^{2}\end{array}$ & 0 \\
\hline $\mathrm{d}\left(\right.$ klojen,$\left.c_{1}\right)$ & $\sqrt{\begin{array}{c}(47-2)^{2}+(1-216)^{2}+(55-44)^{2} \\
+(14-22)^{2}+(106-48)^{2} \\
+(22-22)^{2}+(5-4)^{2}+(0-1)^{2}\end{array}}$ & 227,5983304 \\
\hline $\mathrm{d}\left(\right.$ kedungkandang,$\left.c_{1}\right)$ & $\begin{array}{c}(2-2)^{2}+(2-216)^{2}+(38-44)^{2} \\
+(4-22)^{2}+(4-48)^{2} \\
+(10-22)^{2}+(3-4)^{2}+(0-1)^{2}\end{array}$ & 219,6315096 \\
\hline $\mathrm{d}\left(\right.$ sukun,$\left.c_{1}\right)$ & $\begin{array}{c}(2-2)^{2}+(11-216)^{2}+(14-44)^{2} \\
+(1-22)^{2}+(4-48)^{2} \\
+(4-22)^{2}+(0-4)^{2}+(0-1)^{2}\end{array}$ & 213,6422243 \\
\hline $\mathrm{d}\left(\right.$ lowokwaru, $\left.c_{1}\right)$ & $\begin{array}{c}(0-2)^{2}+(1-216)^{2}+(15-44)^{2} \\
+(3-22)^{2}+(8-48)^{2} \\
+(1-22)^{2}+(0-4)^{2}+(0-1)^{2}\end{array}$ & 222,4612326 \\
\hline
\end{tabular}

Pada tabel 3 merupakan penghitungan jarak data dengan centroid 1 menggunakan rumus pada persamaan (1) di mana variable $\mathrm{x}$ adalah nilai data yang akan dialokasikan dan nilai y adalah nilai cluster awal yaitu cluster 1 . 
Tabel 4. Pengulangan 1 Perhitungan Jarak Centroid 2

\begin{tabular}{ccc}
\hline Jarak data dengan Centroid 2 & Euclidian distance & Hasil \\
\hline $\mathrm{d}\left(\right.$ blimbing, $\left.c_{2}\right)$ & $\sqrt{\begin{array}{r}(2-47)^{2}+(216-1)^{2}+(44-55)^{2} \\
+(22-14)^{2}+(48-106)^{2} \\
+(22-22)^{2}+(4-5)^{2}+(1-0)^{2}\end{array}}$ & 227,5983304 \\
$\mathrm{~d}\left(\right.$ klojen, $\left.c_{2}\right)$ & $\sqrt{\begin{array}{r}(47-47)^{2}+(1-1)^{2}+(55-55)^{2} \\
+(14-14)^{2}+(106-106)^{2} \\
+(22-22)^{2}+(5-5)^{2}+(0-0)^{2}\end{array}}$ & 0 \\
$\mathrm{~d}\left(\right.$ kedungkandang, $\left.c_{2}\right)$ & $\sqrt{\begin{array}{r}(2-47)^{2}+(2-1)^{2}+(38-55)^{2} \\
+(4-14)^{2}+(4-106)^{2}\end{array}}$ & 113,872736 \\
$\mathrm{~d}\left(\right.$ sukun, $\left.c_{2}\right)$ & $\sqrt{+(10-22)^{2}+(3-5)^{2}+(0-0)^{2}}$ & \\
$\mathrm{~d}\left(\right.$ lowokwaru, $\left.c_{2}\right)$ & $\sqrt{\begin{array}{r}(2-47)^{2}+(11-1)^{2}+(14-55)^{2} \\
+(1-14)^{2}+(4-106)^{2} \\
+(4-22)^{2}+(0-5)^{2}+(0-0)^{2}\end{array}}$ & 121,3589717 \\
& $\sqrt{\begin{array}{l}(0-47)^{2}+(1-1)^{2}+(15-55)^{2} \\
+(3-14)^{2}+(8-106)^{2} \\
+(1-22)^{2}+(0-5)^{2}+(0-0)^{2}\end{array}}$ & 118,3215957 \\
&
\end{tabular}

Pada tabel 4 merupakan penghitungan jarak data dengan centroid 1 menggunakan rumus persamaan (1) di mana variable $\mathrm{x}$ adalah nilai data yang akan dialokasikan dan nilai y adalah nilai cluster awal yaitu cluster 2

Tabel 5. Pengulangan 1 Perhitungan Jarak Centroid 3

\begin{tabular}{|c|c|c|}
\hline Jarak data dengan Centroid 3 & Euclidian distance & Hasil \\
\hline $\mathrm{d}\left(\right.$ blimbing,$\left.c_{3}\right)=$ & $\sqrt{\left(\begin{array}{c}(2-2)^{2}+(216-2)^{2}+(44-38)^{2} \\
+(22-4)^{2}+(48-4)^{2} \\
+(22-10)^{2}+(4-3)^{2}+(1-0)^{2}\end{array}\right.}$ & 219,6315096 \\
\hline $\mathrm{d}\left(\right.$ klojen,$\left.c_{3}\right)$ & $\sqrt{(47-2)^{2}+(1-2)^{2}+(55-38)^{2}} \begin{array}{c}+(14-4)^{2}+(106-4)^{2} \\
+(22-10)^{2}+(5-3)^{2}+(0-0)^{2}\end{array}$ & 113,872736 \\
\hline $\mathrm{d}\left(\right.$ kedungkandang, $\left.c_{3}\right)$ & $\sqrt{(2-2)^{2}+(2-2)^{2}+(38-38)^{2}} \begin{array}{c}+(4-4)^{2}+(4-4)^{2} \\
+(10-10)^{2}+(3-3)^{2}+(0-0)^{2}\end{array}$ & 0 \\
\hline $\mathrm{d}\left(\right.$ sukun,$\left.c_{3}\right)$ & $\sqrt{(2-2)^{2}+(11-2)^{2}+(14-38)^{2}} \begin{array}{c}+(1-4)^{2}+(4-4)^{2} \\
+(4-10)^{2}+(0-3)^{2}+(0-0)^{2}\end{array}$ & 26,66458325 \\
\hline $\mathrm{d}\left(\right.$ lowokwaru, $\left.c_{3}\right)$ & $\begin{array}{c}(0-2)^{2}+(1-2)^{2}+(15-38)^{2} \\
+(3-4)^{2}+(8-4)^{2} \\
+(1-10)^{2}+(0-3)^{2}+(0-0)^{2}\end{array}$ & 25,3179778 \\
\hline
\end{tabular}

Pada tabel 5 merupakan penghitungan jarak data dengan centroid 1 menggunakan rumus (1) di mana variable $\mathrm{x}$ adalah nilai data yang akan dialokasikan dan nilai y adalah nilai cluster awal yaitu cluster 3

Hasil perhitungan pada langkah pertama menghasilkan nilai jarak masing-masing data terhadap tiap centroid. Langkah selanjutnya adalah memasukan masing-masing data ke dalam cluster. Memasukan data ke dalam cluster dengan melihat jarak data terpendek. 
Tabel 6. Hasil Pengulangan 1

\begin{tabular}{ccccccc}
\hline Kecamatan & D1 & D2 & D3 & Cluster 1 & Cluster 2 & Cluster 3 \\
\hline Blimbing & 0 & 227,5983304 & 219,6315096 & Ok & & \\
Klojen & 227, & 0 & 113,872736 & & Ok & \\
& 2113554 & & & & & Ok \\
Kedungkandang & 219, & 113,872736 & 0 & & \\
& 6315096 & & & & Ok \\
Sukun & 213, & 121,3589717 & 26,66458325 & & & Ok \\
lowokwaru & 6422243 & 222, & 118,3215957 & 25,3179778 & & \\
& 4882019 & & & & \\
\hline
\end{tabular}

Pada tabel 6, Kecamatan Blimbing masuk pada cluster 1 karena jarak D1 merupakan Jarak terpendek. Kecamatan Klojen masuk pada cluster 2 karena jarak D2 merupakan jarak terpendek. Kecamatan Kedungkandang masuk pada cluster 3 karena jarak D3 merupakan jarak terpendek. Kecamatan Sukun masuk pada cluster 3 karena jarak D3 merupakan jarak terpendek. Kecamatan Lowokwaru masuk pada cluster 3 karena jarak D3 merupakan jarak terpendek.

Tabel 7. Penetapan Cluster Pengulangan 2

\begin{tabular}{ccccccccc}
\hline Cluster & Saos & Tempe/tahu & Snack & Roti & Kue & Minuman & Masakan & $\begin{array}{c}\text { Kerajinan } \\
\text { tangan }\end{array}$ \\
\hline C1 & 2 & 216 & 44 & 22 & 48 & 22 & 4 & 1 \\
C2 & 47 & 1 & 55 & 14 & 106 & 22 & 5 & 0 \\
C3 & 1.3333 & 4.6667 & 22.3333 & 2.6667 & 5.3333 & 5 & 1 & 0 \\
\hline
\end{tabular}

Tentukan centroid baru untuk melakukan pengulangan berikutnya dengan cara menghitung rata-rata tiap cluster. Jumlahkan seluruh anggota masing-masing cluster dan dibagi jumlah anggotanya. Centroid 1 dan Centroid 2 hanya memiliki satu anggota maka nilai Centroid 1 dan Centroid 2 tidak berubah seperti pada tabel 6. Langkah berikutnya setelah Centoid baru ditentukan, hitung kembali jarak masing-masing data terhadap Centroid baru seperti pada tabel 7 , tabel 8, dan tabel 9 .

Tabel 8. Pengulangan 2 Jarak Centroid 3

\begin{tabular}{|c|c|c|}
\hline Jarak data dengan Centroid 3 & Euclidian distance & Hasil \\
\hline $\mathrm{d}\left(\right.$ blimbing, $\left.c_{3}\right)$ & & 218,2312738 \\
\hline & $\begin{array}{c}(2-1.3333333)^{2} \\
+(216-4.6666667)^{2} \\
+(44-22.3333333)^{2} \\
+(22-2.6666666)^{2} \\
+(48-5.3333333)^{2} \\
+(22-5)^{2}+(4-1)^{2}+(1-0)^{2}\end{array}$ & \\
\hline $\mathrm{d}\left(\right.$ klojen,$\left.c_{3}\right)$ & $\begin{array}{c}\quad(47-1.3333333)^{2} \\
+(1-4.6666667)^{2} \\
+(55-22.3333333)^{2} \\
+(14-2.6666666)^{2} \\
+(106-5.3333333)^{2} \\
\sqrt{+(22-5)^{2}+(5-1)^{2}+(0-0)^{2}}\end{array}$ & 117,1888315 \\
\hline $\mathrm{d}\left(\right.$ kedungkandang, $\left.c_{3}\right)$ & $\begin{array}{c}(2-1.3333333)^{2} \\
+(2-4.6666667)^{2} \\
+(38-22.3333333)^{2} \\
+(4-2.6666666)^{2} \\
+(4-5.3333333)^{2} \\
+(10-5)^{2}+(3-1)^{2}+(0-0)^{2}\end{array}$ & 16,89838918 \\
\hline
\end{tabular}




\begin{tabular}{|c|c|c|}
\hline $\mathrm{d}\left(\right.$ sukun, $\left.c_{3}\right)$ & $\begin{array}{c}(2-1.3333333)^{2} \\
+(11-4.6666667)^{2} \\
+(14-22.3333333)^{2} \\
\sqrt{+(1-2.6666666)^{2}+(4-5.3333333)^{2}} \\
+(4-5)^{2}+(0-1)^{2}+(0-0)^{2}\end{array}$ & 10,79608977 \\
\hline $\mathrm{d}\left(\right.$ lowokwaru, $\left.c_{3}\right)$ & $\begin{array}{c}\quad(0-1.3333333)^{2} \\
+(1-4.6666667)^{2} \\
+(15-22.3333333)^{2} \\
+(3-2.6666666)^{2} \\
+(8-5.3333333)^{2} \\
+(1-5)^{2}+(0-1)^{2}+(0-0)^{2}\end{array}$ & 9,655165566 \\
\hline
\end{tabular}

Kelompokan lagi masing-masing data sesuai jarak terdekat dengan Centroidnya seperti pada tabel 8. Hasil pengelompokan digunakan untuk melihat apakah data pada cluster berubah.

Tabel 9. Hasil Pengulangan 2

\begin{tabular}{|c|c|c|c|c|c|c|}
\hline Kecamatan & D1 & $\mathrm{D} 2$ & D3 & Cluster 1 & Cluster 2 & Cluster 3 \\
\hline Blimbing & 0 & 227,5983304 & 218.2312738 & $\mathrm{Ok}$ & & \\
\hline Klojen & $\begin{array}{c}227 \\
2113554\end{array}$ & 0 & 117.1888315 & & $\mathrm{Ok}$ & \\
\hline Kedungkandang & $\begin{array}{c}218 \\
2292373\end{array}$ & 113,872736 & 16.89838918 & & & Ok \\
\hline Sukun & $\begin{array}{c}222, \\
4882019\end{array}$ & 121,3589717 & 10.79608977 & & & Ok \\
\hline lowokwaru & $\begin{array}{c}222, \\
4882019\end{array}$ & 118,3215957 & 9.655165566 & & & Ok \\
\hline
\end{tabular}

Berdasarkan hasil Pengulangan 2 pada tabel 9, hasil cluster untuk tiap data sama dengan pengulangan pertama, maka proses perhitungan sudah selesai.

Tabel 9 menghasilkan penempatan kecamatan pada masing-masing cluster. Kecamatan Blimbing masuk pada cluster 1 dengan prioritas tinggi. Kecamatan Klojen masuk pada cluster 2 dengan prioritas sedang. Kecamatan Kedungkandang, Kecamatan Sukun, dan Kecamatan Lowokwaru masuk pada cluster 3 dengan prioritas rendah. Masing-masing Kecamatan tersebut mendapat kan prioritas pengembangan pasar dari Dinas Koperasi dan Usaha Mikro, Kecil, dan Menengah Kota Malang.

\section{KESIMPULAN}

Dari hasil penelitian yang dilakukan, dapat disimpulkan bahwa penelitian ini mengelompokkan UMKM di tiap Kecamatan di Kota Malang menjadi 3 cluster menggunakan metode cluster K-means. Hasil perhitungan menunjukan kecamatan Blimbing masuk pada cluster 1 yaitu cluster tinggi, Kecamatan Klojen masuk pada cluster 2 yaitu cluster sedang, dan kecamatan Kedungkandang, Sukun, Lowokwaru pada cluster 3 yaitu cluster rendah. KecamatanKecamatan tersebut akan mendapat perhatian pemerintah terkait penetapan strategi pemasaran untuk mengembangkan pasar berdasarkan tingkat prioritas masing-masing cluster.

\section{SARAN}

Algoritma K-means yang digunakan telah menghasilkan hasil cukup akurat untuk mengelompokan data ke dalam beberapa cluster. Penelitian ini masih belum sempurna maka perlu dilakukan penelitian yang lebih lanjut lagi.

\section{DAFTAR PUSTAKA}

[1] Suci, Y. R., 2017, Perkembangan UMKM (Usaha mikro kecil dan menengah) di Indonesia. Cano Ekonomos, Vol. 1(1), 51-58. 
[2] Ediyanto, M. N. M., \& Satyahadewi, N., 2013, Pengklasifikasian Karakteristik Dengan Metode K-Means Cluster Analysis. Bimaster, Vol. 2(2).

[3] Agusta, Y., 2007, K-Means-Penerapan, Permasalahan dan Metode Terkait. Jurnal Sistem dan Informatika, Vol.3(1), 47-60.

[4] Siska, S., T,. 2016, Analisa dan Penerapan Data Mining Untuk Menentukan Kubikasi Air Terjual Berdasarkan Pengelompokan Pelanggan Menggunakan Algoritma K-Means Clustering, Jurnal Teknologi Informasi \& Pendidikan, Vol. 9(1).

[5] Alfarazy Syam, Febrizal, 2017, Implementasi Metode Klastering K-Means Untuk Mengelompokan Hasil Evaluasi Mahasiswa, Jurnal Ilmu Komputer dan Bisnis, Vol8(1).

[6] Sudaryanto, R., \& Wijayanti, R. R., 2013, Strategi pemberdayaan UMKM menghadapi pasar bebas Asean. Pusat Kebijakan Ekonomi Makro. Badan Kebijakan Fiskal. Kementerian Keuangan, Jakarta.

[7] M. W. Talakua, Z. A. Leleury, A. W. Talluta, 2017, Analisis cluster dengan Menggunakan Metode K-Means Untuk Pengelompokan Kabupaten/Kota di Provinsi Maluku Berdasarkan Indikator Indeks Pembangunan Manusia Tahun 2014. Jurnal Ilmu Matematika dan Terapan, Vol 11(2), 119-118.

[8] Bastian, Ade, Sujadi, Harun dan Febrianto Gigin, 2018, Penerapan Algoritma K-Means Clustering Analysis Pada Penyakit Menular Manusia (Studi Kasus Kabupaten Majalengka), Jurnal Sistem Informasi, Vol 14(1).

[9] Gustientiedina, Adiya, Hasmil M., Desnelita Yenny, 2019, Penerapan Algorita K-means Untuk Clustering Data Obat-Obatan pada RSUD Pekanbaru, Jurnal Nasional Teknologi Dan Sistem Informasi, Vol 5(1).

[10] Nur, Fauziah, Prof. Zarlis, M., Dr. Benyamin Nasution, Benny, 2017, Penerapan Algoritma K-Means Pada Siswa Baru SEkolah Menengah Kejuruan Untuk Clustering Jurusan, Jurnal Nasional Informatika dan Teknologi Informatika, Vol 1(2).

[11] Asroni \& Adrian, Ronald, 2015, Penerapan Metode K-Means Untuk Clustering Mahasiswa Berdasarkan NIlai Akademik Dengan Weka Interface Studi Kasus Pada Jurusan Teknik Informatika UMM Magelang, Jurnal Ilmiah Semesta Teknika Vol 18(1), 76-82.

[12] Priyatman, Hendro, Sajid, Fahmi, Haldivany, 2019, KLasterisasi Menggunakan Algoritma K-Means Clustering Untuk Memprediksi Waktu Kelulusan Mahasiswa, Jurnal Edukasi dan Penelitian Informatika, Vol 5(1).

[13] Fa'rifah, R. Y., dan Poerwanto B., 2016, Analisis Cluster K-Means Dalam Pengelompokan Kemampuan Mahasiswa, Indonesian Journal of Fundamental Sciences, Vol 2(2). 